\title{
Dental Care Service Satisfaction by the Characteristics of Users at a Dental Center for the Disabled in a Region
}

\author{
Hyo Jeong Park', Jae Ra Lee ${ }^{2}$ \\ Department of Dental Hygiene, ${ }^{1}$ Yeungnam University College, Daegu, ${ }^{2}$ Mokpo Science University, Mokpo, Korea
}

\begin{abstract}
Objective: This study aimed to see the characteristics and satisfaction factors of users at a dental center for the disabled in Gwangju and present basic data that could provide high-quality healthcare service. Data were collected from 218 users, and result were obtained as follow.
\end{abstract}

\begin{abstract}
Methods: 218 users of Gwangju dental center for the disabled participated in this study from July 27 to October 31, 2015. Frequency analysis was performed for the general characteristics and utilization status; the mean and standard deviation were estimated for dental care service satisfaction; independent t-test and one-way ANOVA were performed for the mean differences in satisfaction by the general characteristics; and Scheffe test was carried out in case of significant differences.
\end{abstract}

Results: Mentally disordered patients or users accompanying them were generally most satisfied; in particular, satisfaction with the facility environment and medical technology differed statistically significantly.

Conclusion: On the basis of these results, it is necessary to make users of dental centers for the disabled more satisfied by making healthcare service at the center more accessible and by giving more support to the facility environment and medical technology for each disability type with the objective of making the center more usable.

Keywords: dental center for the disabled, dental care, disabled, satisfaction

\section{Introduction}

World Health Organization (WHO) has announced 1981 as an International Year of Disabled Persons, and South Korea has also seen an increase in the number of disabled persons as approximately 100,000 persons were registered as disabled each year between 1988 and 2018 [1]. This may have resulted

\section{Corresponding author Hyo Jeong Park}

E-mail: park9906@ync.ac.kr

(iD) https://orcid.org/0000-0002-5075-6856

Received November 17, 2021, Revised December 16, 2021 , Accepted December 22, 2021 from the increase in the number of registrations for acquired disorder because the aged population with chronic disease has increased with the development of medical technology, and the survival rate of children with innate disorder has become higher. The abolition of the disability rating system and division of disability into 2 grades-severe and mild/moderate- in July 2018 has required a more complicated welfare system than those criteria applied to date and contributed to the reinforcement of public oral health and concerns about dental treatment for the disabled in the oral care area [2]. The disabled have rights to get service facilitating their social integration and reintegration in such areas as disability treatment, rehabilitation, and education and are not subjected to discrimination due to their disabilities [3]. Although South

Copyright (C) 2021. Korean Academy of Preventive Dentistry.

This is an Open Access article distributed under the terms of the Creative Commons Attribution Non-Commercial License (http://creativecommons.org/licenses/ by-nc/4.0) which permits unrestricted non-commercial use, distribution, and reproduction in any medium, provided the original work is properly cited. 
Korea has established dental treatment institutions for the disabled and operated the central dental center for the disabled, 10 regional dental centers for the disabled, and oral health rooms to provide comparable healthcare service to both disabled and non-disabled persons, available oral treatment service is still limited in practice, compared to the increasing number of disabled persons [4]. In addition, those centers are hard to access and most of them have difficulty due to medical charges not covered by insurance. It is therefore necessary to make diverse approaches to better oral health and dental care specialists need to take interest in oral health for the disabled and make efforts to solve the problem [5].

The Ministry of Health and Welfare supports establishment and operation of 10 dental centers for the disabled around the country and has municipal and provincial governments run the Project of Dental Centers for the Disabled so that disabled persons in blind spots of dental care service can get timely treatment [6]. Among these, Gwangju dental center for the disabled in Chonnam National University Dental Hospital was first selected in 2009 and opened on May 24, 2011 to start a dental center program and has run the program actively. While the dental center program for the disabled has increased in quantity, no research has been conducted on the utilization status and the facility environment in terms of the centers. Relevant studies include Chang [7] and Cho et al. [8] on the status of dental treatment for the disabled and their satisfaction and Park et al. [9] on status of job satisfaction in dental care specialists at dental centers for the disabled; there is little research on the characteristics of satisfaction of users at regional dental centers for the disabled. This study aimed to see the characteristics and satisfaction factors of users at a current dental center for the disabled in Gwangju and present basic data that could provide high-quality healthcare service.

\section{Materials and Methods}

\section{Subjects}

A self-administered questionnaire was used to collect and analyze data from 218 users of Gwangju dental center for the disabled from July 27 to October 31, 2015. This study was conducted with the approval of the Institutional Review Board in Chonnam National University Dental Hospital (IRB no. 1040198-150629-HR-031-02) in 2015.

\section{Instruments}

A five-point likert scale ( 5 totally agree, 4 agree, 3 average, 2 disagree, and 1 totally disagree) was used, based on the structured one in the previous research, with a total of 40 items: 24 for satisfaction with 'facility environment' (4), 'utilization procedure' (5), 'medical technology' (4), 'medical expenses' (4), 'friendliness' (3), and 'general satisfaction' (3), 4 for the general characteristics, 5 for the disability characteristics, and 7 for dental care service utilization status. This instrument had Cronbach's $\alpha=0.932$ for reliability.

\section{Statistical analysis}

The collected data were analyzed using an IBM SPSS Statistics 21.0 (IBM Co., Armonk, NY, USA) program. Frequency analysis was performed for the general characteristics and utilization status; the mean and standard deviation were estimated for dental care service satisfaction; independent t-test and one-way ANOVA were performed for the mean differences in satisfaction by the general characteristics; and Scheffe test was carried out in case of significant differences.

\section{Results}

\section{General characteristics}

As for the general characteristics of the respondents, $51.8 \%$ were male, and $48.2 \%$ were female; $26.6 \%$ were aged $40-49$, $26.1 \%$ were less than $29,23.9 \%$ were 50 or older, and $23.4 \%$ were $30-39.33 .5 \%$ were physically disabled, $30.3 \%$ had other types of disabilities, $28.4 \%$ were mentally retarded, and $7.8 \%$ had multiple disorders combined with mental retardation; $41.3 \%$ had national health insurance, $36.7 \% \%$ were under Type 1 medical protection, and $17.9 \%$ were under Type 2 medical protection; $81.2 \%$ of the patients were on their revisit and $18.8 \%$ on their first visit (Table 1 ).

Table 1. General characteristics $(\mathrm{N}=218)$

\begin{tabular}{llr}
\hline \multicolumn{1}{c}{ Item } & \multicolumn{1}{c}{ Division } & $\mathrm{N}(\%)$ \\
\hline Sex & Male & $113(51.8)$ \\
& Female & $105(48.2)$ \\
Age & $<29$ & $57(26.1)$ \\
& $30-39$ & $51(23.4)$ \\
& $40-49$ & $58(26.6)$ \\
Disability type & $\geq 50$ & $52(23.9)$ \\
& Physical disabilities & $73(33.5)$ \\
& Mental disorder & $62(28.4)$ \\
& Multiple disorders combined & $17(7.8)$ \\
Medical & with mental retardation & \\
insurance type & $66(30.3)$ \\
& Other types & $39(17.9)$ \\
Visit status & Type 2 medical protection & $90(41.3)$ \\
& Nealth Insurance & $9(4.2)$ \\
& First visit & $41(18.8)$ \\
& Revisit & $177(81.2)$ \\
\hline
\end{tabular}


Table 2. Status of using dental center for the disabled

\begin{tabular}{|c|c|c|}
\hline Item & Division & $\mathrm{N}(\%)$ \\
\hline \multirow[t]{7}{*}{ Transportation } & Public transportation (subway, bus) & $21(9.6)$ \\
\hline & Privately-owned car & $111(50.9)$ \\
\hline & Taxi & $18(8.3)$ \\
\hline & Call taxi for the disabled & $41(18.8)$ \\
\hline & Motorized wheelchair & $7(3.2)$ \\
\hline & Walk & $7(3.2)$ \\
\hline & Other & $13(6.0)$ \\
\hline \multirow{3}{*}{$\begin{array}{l}\text { Number of visit } \\
\text { (Period: } 1 \text { year) }\end{array}$} & $1-5$ & $136(62.4)$ \\
\hline & $6-10$ & $41(18.8)$ \\
\hline & 11 & $41(18.8)$ \\
\hline \multirow[t]{7}{*}{ Motive of use } & Because it is a dental care center specializing in the disabled & $117(53.7)$ \\
\hline & Because of reduction and exemption of medical expenses for disabled patients & $48(22.0)$ \\
\hline & To get dental treatment under general anesthesia & $33(15.1)$ \\
\hline & Because it is near home & $16(7.3)$ \\
\hline & Recommended by other hospitals or other people & $20(9.2)$ \\
\hline & Because of good facilities or equipment & $10(4.6)$ \\
\hline & Other & $5(2.3)$ \\
\hline \multirow[t]{6}{*}{ Via utilization information path } & Guided by health center & $18(8.3)$ \\
\hline & Guided by support center for the disabled & $45(20.7)$ \\
\hline & Guided by community service center & $8(3.7)$ \\
\hline & Recommended by acquaintance & $65(29.8)$ \\
\hline & Through online information retrieval & $29(13.3)$ \\
\hline & Other & $52(24.3)$ \\
\hline \multirow[t]{8}{*}{ Treatment contents } & Regular oral examination & $62(28.4)$ \\
\hline & Dental caries treatment & $69(31.7)$ \\
\hline & Endodontic treatment & $48(22.0)$ \\
\hline & Prosthetic treatment & $52(23.9)$ \\
\hline & Gum treatment & $37(31.4)$ \\
\hline & Tooth extraction & 26 (11.9) \\
\hline & Implantation & $31(14.2)$ \\
\hline & Other & $52(24.3)$ \\
\hline
\end{tabular}

\section{Status of using dental center for the disabled}

$50.9 \%$ visited the center in their own car; $51.4 \%$ had used the center for up to 1 year. $62.4 \%$ used the center $1-5$ times for the past year; $53.7 \%$ used the dental center for the disabled because it is a dental care center specializing in the disabled; $29.8 \%$ were introduced to the center by their acquaintance. The most frequent type of treatment was dental caries treatment $(31.7 \%)$, followed by gum treatment $(31.4 \%)$, regular oral examination $(28.4 \%)$, prosthetic treatment $(23.9 \%)$, and endodontic treatment $(22.0 \%)$ (Table 2$)$.

\section{Satisfaction with dental care service at dental center for the disabled}

The item with which patients themselves were most satisfied in dental care service was 'hygiene in the environment of treatment rooms in the center' $(4.42 \pm 0.73)$, followed by 'examination and treatment by the dentist' $(4.37 \pm 0.62)$, in terms of medical technology and 'reduction and exemption of medical expenses in using the center' $(3.64 \pm 0.99)$ in terms of medical expenses.

The item with which caregivers were most satisfied was 'good answers to questions or full explanation of precautions by medical staff' $(4.27 \pm 0.68)$ in terms of friendliness and 'intention to recommend the center to other disabled persons' in terms of general satisfaction. Like patients, the item with which they were least satisfied was 'reduction and exemption of medical expenses in using the center' in terms of medical expenses (Table 3).

\section{Differences in dental care service satisfaction by disability type}

Mentally disordered patients or users accompanying them were generally most satisfied; in particular, satisfaction with the facility environment and medical technology differed statistically significantly $(\mathrm{p}<0.05)$ (Table 4$)$. 
Table 3. Satisfaction with dental care service at dental center for the disabled

\begin{tabular}{|c|c|c|}
\hline \multirow{2}{*}{ Item } & \multicolumn{2}{|c|}{ Respondent } \\
\hline & Patient & Caregiver \\
\hline \multicolumn{3}{|l|}{ Facility environment } \\
\hline This center is accessible. & $4.14 \pm 0.89$ & $3.78 \pm 0.90$ \\
\hline This center is well equipped with a signboard or guide. & $4.05 \pm 0.91$ & $3.90 \pm 0.91$ \\
\hline Examination rooms and other places in this study have a hygienic environment. & $4.42 \pm 0.73$ & $4.00 \pm 0.73$ \\
\hline $\begin{array}{l}\text { It is easy to get to any facility (treatment room, examination room, } \\
\text { administration department, test room, etc.) or destination within the center. }\end{array}$ & $4.18 \pm 0.70$ & $3.98 \pm 0.71$ \\
\hline This center is well equipped with conveniences for the disabled. & $4.18 \pm 0.70$ & $3.98 \pm 0.71$ \\
\hline \multicolumn{3}{|l|}{ Use procedure } \\
\hline $\begin{array}{l}\text { This center has a convenient procedure for reception, payment, } \\
\text { examination and treatment, and so on. }\end{array}$ & $4.09 \pm 0.78$ & $3.96 \pm 0.76$ \\
\hline This center allows appointment for treatment at my convenience. & $3.64 \pm 1.12$ & $3.73 \pm 0.90$ \\
\hline This center doesn't have long waiting time before getting treatment. & $3.66 \pm 1.06$ & $3.65 \pm 0.94$ \\
\hline This center has a good appointment system. & $4.18 \pm 0.95$ & $4.02 \pm 0.84$ \\
\hline Any complaint or problem is promptly solved. & $4.01 \pm 0.68$ & $3.95 \pm 0.70$ \\
\hline \multicolumn{3}{|l|}{ Medical technology } \\
\hline I am satisfied with my own dentist's service. & $4.37 \pm 0.62$ & $4.18 \pm 0.79$ \\
\hline $\begin{array}{l}\text { This center uses up-to-date medical equipment } \\
\text { and technology appropriate for treatment. }\end{array}$ & $4.16 \pm 0.72$ & $4.08 \pm 0.74$ \\
\hline $\begin{array}{l}\text { The medical staff has expertise and gives dental care service appropriate } \\
\text { for the patient's conditions. }\end{array}$ & $4.31 \pm 0.60$ & $4.20 \pm 0.70$ \\
\hline It makes good collaboration and cooperation with other healthcare institutions. & $3.94 \pm 0.70$ & $4.06 \pm 0.70$ \\
\hline \multicolumn{3}{|l|}{ Medical expenses } \\
\hline $\begin{array}{l}\text { I knew that disabled users of the dental center for the disabled } \\
\text { might have medical expenses reduced or exempted before my visit. }\end{array}$ & $3.74 \pm 1.16$ & $3.51 \pm 1.13$ \\
\hline The payment for using this center is at a proper level. & $3.74 \pm 0.87$ & $3.56 \pm 0.75$ \\
\hline The reduction and exemption of the payment for using this center is at a proper level. & $3.64 \pm 0.99$ & $3.53 \pm 0.78$ \\
\hline I was given full explanation of medical expenses and reduction and exemption of the expenses. & $3.88 \pm 0.92$ & $3.87 \pm 0.79$ \\
\hline \multicolumn{3}{|l|}{ Friendliness } \\
\hline The employee at the reception gave kind responses and explanation. & $4.27 \pm 0.71$ & $3.96 \pm 0.73$ \\
\hline $\begin{array}{l}\text { The medical staff gave kind explanation of symptoms, diagnosis results, } \\
\text { and treatment process and fully reflected the patient's opinions in the medical process. }\end{array}$ & $4.25 \pm 0.64$ & $4.15 \pm 0.74$ \\
\hline The medical staff gave good answers to any question or full explanation of precautions. & $4.29 \pm 0.71$ & $4.27 \pm 0.68$ \\
\hline \multicolumn{3}{|l|}{ General satisfaction } \\
\hline I was given good dental care service equivalent to the payment to this center. & $4.07 \pm 0.69$ & $3.99 \pm 0.69$ \\
\hline I will continue to use this center. & $4.27 \pm 0.65$ & $4.22 \pm 0.71$ \\
\hline I intend to recommend this center to other disabled persons. & $4.25 \pm 0.67$ & $4.23 \pm 0.76$ \\
\hline
\end{tabular}

Values are presented as mean \pm standard deviation.

\section{Discussion}

This study aimed to see the characteristics and satisfaction factors of users at a dental center for the disabled in Gwangju and present a scheme for providing high-quality healthcare service.

$51.8 \%$ were male, and $48.2 \%$ were female; $26.6 \%$ were aged $40-49,26.1 \%$ were less than $29,23.9 \%$ were 50 or older, and $23.4 \%$ were $30-39$. The most frequent type of disabilities was physical disabilities (33.5\%), consistent with the registration status of disabled persons in Jeollanam-do Province as of 2013, as disclosed by the Ministry of Health and Welfare [10].
Oh et al. [11] reported that $80 \%$ of the disabled population were unable to brush their teeth by themselves and relied on others' help to do so and suggested the need to introduce a correct method of toothbrushing on the basis of disability type. The most frequent type of medical insurance was National Health Insurance (41.3\%). Cho [12] and Cho et al. [8] also found that National Health Insurance was the most frequent type of medical security. As for dental care service use status, the respondents were likely to visit a dentist within the past year: $62.4 \%$ used it $1-5$ times for the past year, consistent with Shim et al. [13]. The most frequent path of introduction to the center was recommendation by an acquaintance (29.8\%), and 
Table 4. Differences in dental care service satisfaction by disability type

\begin{tabular}{|c|c|c|c|c|c|}
\hline Item & Division & $\mathrm{M} \pm \mathrm{SD}$ & $\mathrm{F}$ & p-value & Scheffe test \\
\hline \multirow[t]{4}{*}{ Facility environment satisfaction } & Physical disabilities & $3.89 \pm 0.65$ & 2.809 & $0.040^{*}$ & $b>a, c, d^{* *}$ \\
\hline & Mental disorder & $4.18 \pm 0.58$ & & & \\
\hline & Multiple disorders & $4.08 \pm 0.42$ & & & \\
\hline & Other types & $4.08 \pm 0.60$ & & & \\
\hline \multirow[t]{4}{*}{ Use procedure satisfaction } & Physical disabilities & $3.73 \pm 0.74$ & 2.038 & 0.110 & \\
\hline & Mental disorder & $4.01 \pm 0.57$ & & & \\
\hline & Multiple disorders & $3.98 \pm 0.70$ & & & \\
\hline & Other types & $3.83 \pm 0.70$ & & & \\
\hline \multirow[t]{4}{*}{ Medical technology satisfaction } & Physical disabilities & $3.95 \pm 0.61$ & 3.809 & $0.011^{*}$ & $b>a, c, d^{* *}$ \\
\hline & Mental disorder & $4.24 \pm 0.56$ & & & \\
\hline & Multiple disorders & $4.32 \pm 0.42$ & & & \\
\hline & Other types & $4.19 \pm 0.59$ & & & \\
\hline \multirow[t]{4}{*}{ Satisfaction with medical expenses } & Physical disabilities & $3.59 \pm 0.59$ & 1.894 & 0.132 & \\
\hline & Mental disorder & $3.83 \pm 0.63$ & & & \\
\hline & Multiple disorders & $3.66 \pm 0.57$ & & & \\
\hline & Other types & $3.62 \pm 0.67$ & & & \\
\hline \multirow[t]{4}{*}{ Satisfaction with friendliness } & Physical disabilities & $4.05 \pm 0.64$ & 0.836 & 0.476 & \\
\hline & Mental disorder & $4.19 \pm 0.58$ & & & \\
\hline & Multiple disorders & $4.23 \pm 0.51$ & & & \\
\hline & Other types & $4.14 \pm 0.57$ & & & \\
\hline \multirow[t]{4}{*}{ General satisfaction } & Physical disabilities & $4.01 \pm 0.68$ & 2.534 & 0.058 & \\
\hline & Mental disorder & $4.28 \pm 0.65$ & & & \\
\hline & Multiple disorders & $4.19 \pm 0.52$ & & & \\
\hline & Other types & $4.25 \pm 0.53$ & & & \\
\hline
\end{tabular}

$\mathrm{M} \pm \mathrm{SD}=$ mean \pm standard deviation. ${ }^{*} \mathrm{p}<0.05 .{ }^{* *} \mathrm{a}=$ physical disabilities, $\mathrm{b}=$ mental disorder, $\mathrm{c}=$ multiple disorders, $\mathrm{d}=$ other types.

the least frequent one was guidance by a community service center $(3.7 \%)$. This seems to imply that the centers are not effectively publicized but known to the limited targets, such as acquaintances. It is necessary to make positive guidance and public relations (PR)s through diverse PR media and methods with the aim of activating the centers. The most frequent type of treatment was dental caries treatment (31.7\%), followed by gum treatment $(31.4 \%)$, regular oral examination $(28.4 \%)$, prosthetic treatment (23.9\%), and endodontic treatment (22.0\%). Baek and Kong [14] reported that regular oral examination for the disabled is not simply for the purpose of dental care but affects living satisfaction related to individuals' oral functions.

The respondents were least satisfied with medical expenses in dental care service. The majority of disabled persons in the lower income bracket have a poor ability to make a living due to their disabilities and need to pay medical expenses related to rehabilitation or health constantly. The vicious cycle of poverty and poor health puts a burden on the disabled [15], who may give up getting dental care service and neglect any problem due to limited access to dental care institutions and the heavy financial burden for treatment not covered by medical insurance [16]. As for the meaningful differences in satisfaction by disability type, mentally disordered patients or users accompanying them were most satisfied in general. In particular, satisfaction with the facility environment differed statistically significantly. Likewise, Lee [17] on satisfaction with a welfare center program in disabled people also found that the participants with mental disorder were most satisfied. Because mental disorder is very likely to be less affected by the facility environment, it is necessary to take interest in the facility environment and solve any discomfort so that users with physical disabilities and multiple disorders, who are possibly more affected by the facility environment, can be more satisfied. The severely disabled in the dental care area include those who have one or more of 6 (epilepsy, brain lesion, autism, mental, intellectual, and physical disabilities) out of 15 disability types under the provisions of the Act on Welfare of Persons with Disabilities and have got Grade 6 for their disabilities or lower [18]. It is therefore necessary to increase diverse types of reduction and exemption of medical expenses by the lower income bracket, disability type, grade, and so on. This study is expected to be useful in seeing the characteristics and satisfaction factors of users at a dental center for the disabled to make a scheme for providing high-quality healthcare service.

This study is limited to users of a dental center for the disabled in a region and can hardly be generalized into all the dental centers for the disabled; therefore, further research should 
be conducted in users of regional centers constantly to operate and develop the centers successfully by covering utilization status and satisfaction, program contents, and program evaluation.

\section{Conclusion}

The purpose of this study was to see the characteristics and satisfaction factors of users at a dental center for the disabled in Gwangju and present basic data that could provide highquality healthcare service; for this purpose, data were collected from 218 users and analyzed, obtaining the following results:

$1.72 .5 \%$ of the users had used the center; a large number of users went to the center in their own car; it took most of them half an hour to less than an hour to go to the center. The most frequent motive of using this center was the fact that 'it is a dental care center specializing in the disabled'; a large number of users were introduced to it by their acquaintance.

2. Dental care service was divided into 6 areas; facility environment, use procedure, medical technology, medical expenses, friendliness, and satisfaction; the highest mean score was for 'general satisfaction', followed by 'satisfaction with medical technology', 'satisfaction with friendliness', 'satisfaction with the facility environment', 'satisfaction with use procedure', and 'satisfaction with medical expenses'.

3. Mentally disordered patients or users accompanying them were generally most satisfied; in particular, satisfaction with the facility environment and medical technology differed statistically significantly.

On the basis of these results, it is necessary to make users of dental centers for the disabled more satisfied by making healthcare service at the center more accessible and by giving more support to the facility environment and medical technology for each disability type with the objective of making the center more usable.

\section{Conflict of Interest}

No potential conflict of interest relevant to this article was reported.

\section{ORCID}

Hyo Jeong Park, https://orcid.org/0000-0002-5075-6856

Jae Ra Lee, https://orcid.org/0000-0002-2051-4952

\section{References}

1. Cho YH, Kim YJ, Oh YJ, Wang YM, Kim TY. 2019 Statistical of disabilities. Seoul: Korea disabled people's development institute; 2019:25-6.

2. Jung YS, Choi YA, Kang JM, Lee YE, Song KB. Comparison of factors among the regional oral health center for the disabled in Korea. J Korean Soc Dent Hyg 2021;21:183-91.

3. Kim SA, Kim YN, Kim YJ, Park JH, Seo KS, Seo HW, et al. Guidebook to dental care for the disabled. Seoul: The Smile Charity Foundation; 2005.

4. Moon YJ, Yang YM, Kim JG, Baik BJ. A study on the dental treatment under outpatient general anesthesia for disabled at Chonbuk National University Dental Hospital. J Korean Assoc Disabil Oral Health 2012;8:49.

5. Go HJ, Park TJ, Kim EK, Jo HJ, Choi YH, Song KB. A report on the regional oral health centers for the disabled in Korea. $\mathrm{J}$ Korean Dent Assoc 2019;57:8-17.

6. Choi GR. Research on treatment status of the disabled and relevant issues at dental care institutions in South Korea. J Korean Dent Assoc 2000;38:1159-62.

7. Chang JH. Dental treatment under general anesthesia: an overview of clinical characteristics of special needs patients. J Korean Assoc Disabil Oral Health 2014;10:61-7.

8. Cho HL, Kim YJ, Yoon TY. A study on the satisfaction factors of the disabled when using dental care services. J Korean Assoc Disabil Oral Health 2014;10:9-21.

9. Park MJ, Park T, Shin JA, Cho MJ, Kim EK, Song KB, et al. Job satisfaction level of dental staff at oral health centers for people with special needs. J Korean Acad Oral Health 2019;43:14-20.

10. Status of the disabled [Internet]. Daejeon: Statistics Korea [cited 2020 October 20]. Available from: https://kosis.kr/statisticsList/statisticsListIndex.do?vwcd=MT_ZTITLE\&menuId=M_0 1_01

11. OH HM, Lee MG, Lee CH. Oral health care program for the disabled persons using the toothpick tooth-brushing method. Int J Clin Prev Dent 2016;12:243-8.

12. Cho NH. A study on the factors deciding satisfaction of the public dental service for the disabled [thesis]. [Yongin]: Dankook University; 2008.

13. Sim KH, Lee CJ, Kim NJ. The questionnaire study on the oral health status for disabled people in Korea. Int J Clin Prev Dent 2016;12:237-42.

14. Baek KW, Kong EK. Prevention and treatment of oral diseases for the disabled. Int J Clin Prev Dent 2011;7:51-6.

15. Ghang BW, Kwon HS, Kim SR, Kim YS, Kim YH, Kim IS, et al. Dental hygiene care of the handicapped patient. Seoul: Komoonsa; 2004.

16. The Smile Foundation [Internet]. Seoul: The Smile Foundation [cited 2020 Oct 20]. Available from: http://www.smilefund.org /main.html.

17. Lee MJ. A study on the satisfaction level of users with welfare agency programs for the disabled [thesis]. [Daejeon]: Hannam University; 2006.

18. Rehabilitation International Korea [Internet]. Seoul: Rehabilitation International Korea [cited 2020 Oct 20]. Available from: http://www.freeget.net/. 